\title{
Biomarkers, a Useful Correction for Respondent Error in Survey Research
}

\author{
George L. Langelett \\ South Dakota State University, Brookings, USA
}

\begin{abstract}
One long standing limitation of survey research is the issue of respondent error. Until present there have been no research methods able to correct for this problem. In this study we present two approaches to correct for respondent error. In the first approach, we demonstrate how a valid instrument can be used, and the second approach requires two additional indicators. One is used to measure the response error and the second is used to correct for endogeneity. The second half of this study presents possible sources for valid indicators to correct for respondent error and make consistent estimation possible.
\end{abstract}

Keywords: respondent error, neurotransmitters, single nucleotide polymorphism, biomarkers

\section{Introduction}

On November 7th, 2016, the day before the U.S. presidential election, seven of the eight major presidential polls had candidate Hillary Clinton leading candidate Donald Trump by the following percentages: Bloomberg +3, CBS +4, Fox +4 , Reuters +3 , $\mathrm{ABC}+4$, Monmouth +6 , and $\mathrm{NBC}+7$ (source: https://www.realclearpolitics.com). The reality that the next day Donald Trump won the presidential election suggests that in spite of our most sophisticated polling practices, our current modeling techniques in survey research are still susceptible to systematic errors. The purpose of this paper is to address one longstanding problem that cofounds both validity and reliability in survey research, the issue of respondent error.

Within the fields of psychology, business, and economics, the majority of empirical studies use quantitative techniques. For studies using primary data, the most often utilized research tool is the questionnaire (Baruch \& Holtom 2008). For any study using a survey for data collection, there are three possible sources of error. First is the issue of sampling techniques that fail to create a representative sample. If a sample is representative, the survey statistics will produce consistent estimators of the population parameters (Antonakis, Bendahan, Jacquart, \& Lalive, 2010). Second is the broad issue of administrative error. Administrative errors include problems with instrument design, i.e., the validity and reliability of the questionnaire, sample selection errors, and data entry and coding errors. The third major source for problems in survey research is respondent error. Response error includes both respondent bias and nonresponse to either parts of or the entire questionnaire.

In regards to using survey research in order to support causality claims, with proper planning, the researcher can (1) utilize sound sampling methodology to create a representative sample or in the case of unavoidable sample selection bias, use a Heckman correction, and (2) set up controls, including a pilot study,

George L. Langelett, Ph.D., Professor, Department of Economics, South Dakota State University, Brookings, USA. 
peer review, and publishing the underlying data in order to eliminate administrative errors. But the one Achilles-heal that remains an impediment for using survey research to make causality claims is respondent error. Trying to correct for respondent error is difficult because it lies beyond the control of the researcher.

The purpose of this paper is threefold: first to discuss reasons why respondent error occurs, including neurological limits to the human mind. The second purpose is to present new statistical techniques that enable researcher to address the fundamental problem of response error in survey research by utilizing the multiple indicator methodology. The third purpose is to present valid indicators, useful for making corrections. We present an overview of biometric markers to measure activity within the central nervous system, and have potential to be useful as instruments in order to correct for endogeneity caused by respondent error.

In regards to suggestions of using research methods borrowed from cognitive neuroscience to explain behavior, concerns arise regarding any attempt to reduce human emotions, cognition, intentions, and behavior to neuropathways and chemicals in the human brain (Bickle, 2006). In response to these disparagements, we are recommending the utilization of a multiple-measurement approach in order to correct for a deficiency of survey research. Much like a physician, who uses multiple indicators to diagnose a sick patient, including: blood pressure, body temperature, oxygen level, and heart rate, researchers in the social sciences can utilize multiple metrics in order to resolve methodological problems that arise when trying to accurately measure human behavior, with an unobservable component. Our goal is to help researchers establish a broader and a more complete understanding of the issue or construct being investigated, and provide additional evidence for the validity of any inferences being made.

This study will be presented as follows: Part I explores several underlying reasons for the existence of the respondent error; Part II explains why response error leads to inconsistent estimation; Part III presents two different corrections for respondent error; Part IV explains research methods used in neuroscience; Part V presents the role of neurotransmitter in the human brain; Part VI provides measurement procedures; and Part VII presents the possibility of indicators from the human genome.

\section{Limits to Human Cognition and Respondent Error}

When utilizing a self-administered questionnaire in order to better understand the perspective of individuals within a sample, respondent error on behalf of participants will occur for three fundamental reasons. First a distinction must be made between the human brain and the human mind. Much like a computer is a physical box containing hardware, the human brain is the physical organ that contains the biological structures required to create complex thoughts. By contrast the human mind is the consciousness that occurs within the human brain. The mind is an awareness that is composed of thoughts, feelings, and intentions.

In regards to the mind, unfortunately, there are limits to human cognition. Within the human brain many processes are continuously being monitored and controlled, but the mind is not consciously aware of their occurrence. For example, the hypothalamus and the brain stem regulate the automatic nervous system (Purves, Augustine, Fitzpatrick, Hall, LaMantia, McNamara, \& White, 2008). The automatic nervous system controls breathing, cardiac function, digestion, and our endocrine system. So, within the central nervous system, we need to separate the human mind from the brain because there are many conscious and unconscious processes occurring simultaneously. According to Becker, Cropanzano, and Sanfey (2011, p. 941), "A distinction needs to be made between what the brain 'perceives' and what the individual is aware of perceiving. The two do not always go together". Both conscious and unconscious perceptions and processes affect human behavior. The 
problem is that conscious and unconscious neural pathways do not necessarily produce the same conclusions to solving a problem or dilemma (Kolb \& Whishaw, 2009). If the nonconscious pathway, often manifested as either habitual or innate behavior, dictates a person's actions, the subject will be unaware of the actual reason(s) for one's behavior and will have a "blind spot" if asked to explain the reason behind one's choice (Kolb \& Whishaw, 2009). Therefore bounded human consciousness limits participant's ability to accurately answer questions in survey research and contributes to respondent error.

Second, the human brain is made up of three distinct regions. The brainstem, connected to spinal cord, controls internal mechanisms that regulate many basic biological functions, including heart rate and breathing. The limbic region is the emotional core of our brain. Similar to the cap of a mushroom, the cerebral cortex is the outer dome of the brain associate with logic and cognitive function. The second issue that leads to respondent error is that attitudes and opinions arise from two distinctly different regions of the brain. Attitudes based on logic and cognitive reasoning originate in the cerebral cortex; and attitudes resulting from an emotional response are synthesized in the limbic region of the brain (Bear, Connors, \& Paradiso, 2006).

Attitudes based on logic and deliberate reasoning are called "explicit" attitudes, and attitudes originating in the limbic region of our brain and based on emotions are called "implicit" attitudes (Becker et al., 2011; Cunningham, Zelazo, Packer, \& Van Bavel, 2007). Implicit attitudes result from mapping the current stimuli or dilemma with experiences and outcomes stored in long-term memory. The major issue with implicit attitudes is that they often are formulated within the brain but outside of human consciousness (Barsade, Ramarajan, \& Westen, 2009; Westen, 2007). Implicit attitudes, based on old memories and the resulting emotional response, play a role in decision making.

Unfortunately, often survey participants are either unaware of or discount implicit attitudes in favor of explicit attitudes (Barsade et al., 2009; Weston, 2007). Studies based on self-administered questionnaires will be biased to the extent to which participants disregard their implicit attitudes, and the degree to which implicit attitudes affect participant behavioral outcomes. Therefore the magnitude of the response error in self-administrated questionnaires is the product of both the degree of disregarding implicit attitudes, and also the extent to which the participant's explicit and implicit attitudes diverge. Unfortunately, a person's explicit and implicit attitudes often diverge (Liberman, 2007).

Implicit attitudes arise first, are affectively loaded, and remain largely outside of consciousness. Because they arise first, they can short-circuit other beneficial nonconscious and conscious processing. Thus, implicit attitudes can be especially pernicious since they can distort subsequent cognitive processing and bias our decisions and behaviors in detrimental ways. (Becker et al., 2011, p. 942)

The third issue that leads to response error in self-reporting questionnaires is the issue of socially-desirable responding. This is the tendency to answer questions in a manner that will be viewed favorable either by the party administering the survey, or by the norms of society. It often takes the form of embellishing "acceptable" or "good" behavior, and not reporting of "undesirable" conduct. Socially-desirable responding is one form of the self-serving biases (Cialdini \& Goldstein, 2004) and also a self-presentation strategy (Leary \& Kowalski, 1990). Self-presentation strategies may have both external component (impression management) and an internalized component (self-deception) (Paulhus, 1984). Self-presentation strategies often occur when survey topics are high in evaluation (Vazire, 2010; Ganster, Hennessey, \& Luthans, 1983) and also when participants are requested to rate themselves (Borkenau \& Zaltauskas, 2009; Epley \& Dunning, 2000). Thus, as a 
self-servingbias, socially desirable responses are a pervasive problem in self-reporting questionnaires (Ganster, Hennessey, \& Luthans, 1983). In summary, bounded human consciousness, divergent implicit and explicit attitudes, and socially desirable responding contribute to the problem of respondent error.

\section{Why Response Error in Surveys Leads to Inconsistent Estimation}

We will start with the assumptions of a linear regression model:

$$
Y_{i}=b_{0 i}+\sum_{j=1}^{k} b_{i j} x_{i j}+e_{i}
$$

Assumption 1: Each explanatory variable, $\mathrm{x}$, is normally distributed (optional assumption), with negligible measurement error.

Assumption 2: Each explanatory variable, $\mathrm{x}$, has mean $\mu_{x}$ and variance $\sigma_{x}^{2}$; and the residuals, $e_{i}$ are normally distributed: $\mathrm{e} \approx \mathrm{N}\left[0, \sigma_{e}^{2}\right]$, although the normality assumption can be dropped with proper estimation of the sampling distribution.

Assumption 3: Uncorrelated regressors and disturbances: $\operatorname{cov}\left[x_{i j}, e_{i}\right]=0$ for all $\mathrm{i} \& \mathrm{j}$.

To simplify the notation, we will utilize matrix notation: $\mathrm{Y}=\mathrm{BX}+\mathrm{E}$.

Then, we introduce the possibility of respondent error, taken from a completed survey, into the model: $\mathrm{X}+$ $\mathrm{U}=\mathrm{X}^{*}$, where $\mathrm{X}$ is recorded survey response on the survey, $\mathrm{U}$ is unseen respondent error, and $\mathrm{X}^{*}$ is the true (unrecorded) attitude, opinion, or attribute of the respondent, underlying the response $\mathrm{X}$ recorded on the survey. For consistent estimation, we assume $\mathrm{U} \approx \mathrm{N}\left[0, \sigma_{U}^{2}\right]$, but in the case of respondent error $\mathrm{E}(\mathrm{u}) \neq 0$. Therefore, using: $\mathrm{Y}=\mathrm{BX}+\mathrm{E}$, and $\mathrm{X}+\mathrm{U}=\mathrm{X}^{*}$, or $\mathrm{X}^{*}-\mathrm{U}=\mathrm{X}$, yields:

$$
\begin{gathered}
\mathrm{Y}=\mathrm{B}\left(\mathrm{X}^{*}-\mathrm{U}\right)+\mathrm{E}, \\
\text { or } \mathrm{Y}=\mathrm{BX}^{*}-\mathrm{BU}+\mathrm{E} .
\end{gathered}
$$

If $\mathrm{W}$ represents the actual error term, where: $\mathrm{W}=\mathrm{E}-\mathrm{BU}$, then $\mathrm{Y}=\mathrm{BX} *+\mathrm{W}$, but,

$$
\operatorname{Cov}\left[\mathrm{X}^{*}, \mathrm{~W}\right]=\operatorname{Cov}[\mathrm{X}+\mathrm{U}, \mathrm{E}-\mathrm{BU}]=-\mathrm{B} \sigma_{\mathrm{U}}^{2} \neq 0 .
$$

Equation (2) violates Assumption 3, the uncorrelatedness of regressors and disturbances. Thus, the presence of respondent error in survey research leads to the problem of endogeneity, and the regression will not produce consistent estimation.

\section{Two Possible Methods to Correct for Response Error in Survey Research}

Given that respondent error in survey research creates an endogeneity problem, there are two possible corrections for response error, required for consistent estimation. The first approach utilizes an instrumental variable, and intuition behind it is relatively straight forward. The second approach (when a strong instrument is not available), requires two additional indicators, and is relatively more cumbersome to establish consistent estimation.

\section{Approach \#1}

Returning to our source of response error: $X+U=X^{*}$, where $X$ is the recorded response, $U$ is the response error or bias, and $X^{*}$ is the true attribute. Approach $\# 1$ is made possible by the ability to obtain $\mathrm{X}^{*}$ through some other indicator, called $\mathrm{Z}$. Table 1 shows possible sources to calculate $\mathrm{Z}$, to correct for $\mathrm{X}+\mathrm{U}$ in survey research: 
Table 1

Personal Questions With Possible Response Error Correction

\begin{tabular}{|c|c|c|c|}
\hline & Survey question with response error & & Possible correct measurement \\
\hline \multirow{5}{*}{ Participant's } & Weight & \multirow{5}{*}{ Use } & A scale to measure weight \\
\hline & Age & & A birth certificate \\
\hline & Income & & Tax returns \\
\hline & Use illegal drugs & & Urine drug test \\
\hline & Diet & & Feces sample \\
\hline
\end{tabular}

In the case of $\mathrm{Z}=\mathrm{X}+\mathrm{U}$, the correction for response error is straight forward. Substituting $\mathrm{Z}$ in for $\mathrm{X}+\mathrm{U}$, and appealing to large sample properties, consistent estimation becomes possible. Through substitution, we obtain $\mathrm{Y}=B_{Z} \mathrm{Z}+E_{Z}$, where $\operatorname{Cov}\left[\mathrm{Z}, E_{z}\right]=0$.

Or within the broader context of a survey sample, $Z$ could also be viewed as an instrumental variable. Recall that consistency in least squares estimation, for:

$$
\mathrm{Y}=\mathrm{BX}+\mathrm{E} \text {, consistency depends on } \operatorname{plim} \frac{1}{n}\left[\mathrm{X}^{\prime} \mathrm{E}\right]=0 .
$$

Then with the use of an instrumental variable $Z, b_{Z}=\left[Z^{\prime} X\right]^{-1}\left[Z^{\prime} Y\right]$, consistency of $b_{z}$ depends on: plim $\frac{1}{n} b_{z}=\operatorname{plim} \frac{1}{n}\left[Z^{\prime} \mathrm{X}\right]^{-1} \operatorname{plim}\left[\frac{1}{n} Z^{\prime}(\mathrm{XB}+\mathrm{E})\right]$

$\left.=\mathrm{B}+\operatorname{plim} \frac{1}{n}\left[\mathrm{Z}^{\prime} \mathrm{X}\right]^{-1} \operatorname{plim}\left[\frac{1}{n} \mathrm{Z}^{\prime} \mathrm{E}\right)\right]=\mathrm{B}$.

Thus, $b_{z}=\mathrm{B}$, and we have consistent estimation.

\section{Approach \#2}

In the absence of an accurate alternative measurement, the dueltasks of detecting and correcting for response error in survey research become significantly more challenging undertakings. Let us start again with what we know: $\mathrm{Y}=\mathrm{BX}+\mathrm{E}$, and

$X+U=X^{*}$, thus $Y=B X^{*}-B U+E$. If we substitute $\Theta=-B$, we have: $Y=B X^{*}+\Theta U+E$. If $U$ was observable, we could estimate unbiased coefficients for both $\mathrm{B}$ and $\Theta$. Unfortunately, $\mathrm{U}$ is unobservable response error, and both $B$ and $\Theta$ will depend on the magnitude of $U$. Even though $U$ is unobservable, all hope is not lost.

If the variance of $\mathrm{U}, \sigma_{U}^{2}$ can be estimated, then consistent estimation becomes possible.

$S_{X Y} /\left(S_{X X}+\sigma_{U}^{2}\right)$ will produce consistent estimators of B. Therefore, although we may not be able to directly detect or correct for response error from a survey, if an alternative methodology exists, it is possible to address respondent error.

\section{Detecting Respondent Error}

Detecting respondent error in survey research will require the use of a second indicator. A second indicator may be created through asking a participant's boss, coworker, or significant other, about that person, and his/her attribute, attitude, or opinion that is potentially suspect. For example, the researcher may ask a worker, named Johnny, how motivated he is at work. Then, for a second indicator, the researcher asks the shift supervisor about Johnny's level of on-the-job motivation. With the presence of an additional indicator, measurement of response error becomes possible with the use of a Hausman (1978) test. 
Let $\mathrm{x}$ be the vector of response in question, recorded on the survey instrument in the survey, and let $\mathrm{I}_{1}$ be the vector of corresponding response recorded from the additional indicator. Based on the hypothesis that plim $\left(x-I_{1}\right)=0$, testing for the presence of measure error becomes possible. If measurement error is not present, the vector $\mathrm{x}$ is both consistent and efficient. But if measurement error has occurred, $\mathrm{x}$ is not consistent (Hausman, 1978). Therefore in the case of no measurement error: plim $\left(b_{x}-b_{I}\right)=0$.

Using a Wald test to test if a new set of parameters add any significant information to the model, the Wald test becomes a Chi-square test.

The Wald test becomes: $\left(\mathrm{b}_{\mathrm{x}}-\mathrm{b}_{\mathrm{I}}\right)^{\prime}\left[\left(\mathrm{CM}_{\mathrm{x}}-\mathrm{CM}_{\mathrm{I}}\right)\right]^{-1}\left(\mathrm{~b}_{\mathrm{x}}-\mathrm{b}_{\mathrm{I}}\right) \approx \chi^{2}$

Where: $\mathrm{CM}_{\mathrm{x}}$ is the covariance matrix for $\mathrm{X}, \mathrm{CM}_{\mathrm{X}}=\mathrm{s}^{2}\left(\mathrm{X}^{\prime} \mathrm{X}\right)^{-1}$ and $\mathrm{CM}_{\mathrm{I}}$ is the covariance matrix for I, the additional indicator: $\mathrm{CM}_{\mathrm{I}}=\mathrm{s}^{2}\left[\mathrm{X}^{\prime} \mathrm{I}\left(\mathrm{I}^{\prime} \mathrm{I}\right)^{-1} \mathrm{I}^{\prime} \mathrm{X}\right]^{-1}$.

The critical values for the Wald test can be referenced in a Chi-Square table.

\section{Correcting for Respondent Error}

Without access to a strong instrument, correcting for respondent error will require the use of two separate indicators, in additional to the response given on the self-administered questionnaire. Based on the work of Woolridge (2010) the multiple indicator solution provides a working framework for resolving the issue of consistent estimation, given presence of response error. The intuition behind this approach is that two additional indicators are required. The first indicator is needed in order to estimate the magnitude of the response error, and the second indicator is required in order to address the problem of endogeneity created by the unobserved respondent error.

\section{Step 1}

Start with the regression based on the self-reported survey questionnaire:

$$
\mathrm{Y}=\mathrm{B}_{\mathrm{X}} \mathrm{X}+\mathrm{B}_{\mathrm{A}} \mathrm{A}+\mathrm{E} \text {, }
$$

where $\mathrm{X}$ is the matrix of regressors, and $\mathrm{A}$ is the response in question. A may be an attribute, opinion, or attitude, and includes a possible error: $\mathrm{A}=\mathrm{A}^{*}+\mathrm{U}$, where $\mathrm{A}^{*}$ is the true attribute and $\mathrm{U}$ is the respondent error, of unknown magnitude.

Two additional indicators of $\mathrm{A}$ are required:

Indicator 1: $\mathrm{I}_{1}=\alpha_{1}+\alpha_{A} \mathrm{~A}+\mathrm{E}_{\mathrm{I} 1}$

Indicator 2: $\mathrm{I}_{2}=\lambda_{1}+\lambda_{A} \mathrm{~A}+\mathrm{E}_{\mathrm{I} 2} \quad$ Where: $\alpha_{A} \neq 0$ and $\lambda_{A} \neq 0$.

And $\operatorname{Cov}\left[\mathrm{A}, \mathrm{E}_{\mathrm{I} 1}\right]=\operatorname{Cov}\left[\mathrm{A}, \mathrm{E}_{\mathrm{I} 2}\right]=\operatorname{Cov}\left[\mathrm{X}, \mathrm{E}_{\mathrm{I} 1}\right]=\operatorname{Cov}\left[\mathrm{X}, \mathrm{E}_{\mathrm{I} 2}\right]=\operatorname{Cov}\left[\mathrm{E}_{\mathrm{I} 1}, \mathrm{E}_{\mathrm{I} 2}\right]=0$.

For purposes of measuring the magnitude of the error provided in the participant's response to each question asked in the survey, Indicator 1 should be the same instrument given to a corresponding individual who knows the tendencies and attitudes of the participant. Next we rearrange Indicator $1: A=\left(I_{1}-\alpha_{1}\right.$ $\left.\mathrm{E}_{\mathrm{I} 1}\right) / \alpha_{A}$ and $\theta_{\mathrm{A}}=\mathrm{B}_{\mathrm{A}} / \alpha_{A}$.

Insert Indicator 1 into the survey questionnaire regression Equation (3) to obtain:

$$
\mathrm{Y}=\mathrm{B}_{\mathrm{X}} \mathrm{X}+\theta_{\mathrm{A}} \mathrm{I}_{1}-\theta_{\mathrm{A}} \alpha_{1}-\theta_{\mathrm{A}} \mathrm{E}_{\mathrm{I} 1}+\mathrm{E} .
$$

The intuition behind this equation is we are now using the information in $\mathrm{E}_{\mathrm{I} 1}$ to control for the response error in embedded within A. But endogeneity still remains a problem in Equation (4), as $\mathrm{I}_{1}$ and $\mathrm{E}_{\mathrm{I} 1}$ are correlated via Indicator 1, and a single monotonic transformation applied to both, does not alter the correlation between two variables. 


\section{Step 2}

Therefore to resolve this issue of endogeneity, we will use $I_{2}$ as an instrument for $I_{1}$. The task of $I_{2}$ to be a valid instrument, requires $\mathrm{I}_{2}$ to be correlated with $\mathrm{A}$, but uncorrelated with $\mathrm{E}_{\mathrm{I} 1}$. This suggests that the second indicator should not simply be the same survey questionnaire given to a third person to answer. With the use of an additional valid independent indicator, a researcher can utilize the information in Indicator 2, because $\mathrm{I}_{2}$ is correlated with $\mathrm{A}$, but not with $\mathrm{E}_{\mathrm{I} 1}$. Define two new regressions:

$$
\begin{gathered}
\mathrm{I}_{1}=\Phi_{1}+\Phi_{2} \mathrm{I}_{2}+\Phi_{x} \mathrm{X}+\delta_{\mathrm{I}_{1}} \\
\widehat{\mathrm{E}}_{\mathrm{I} 1}=\gamma_{\delta} \hat{\delta}_{\mathrm{I}_{1}}+\mathrm{V}_{1}
\end{gathered}
$$

where $\widehat{\mathrm{E}}_{\mathrm{I} 1}$ and $\hat{\delta}_{\mathrm{I}_{1}}$ are fitted residuals, $\delta_{\mathrm{I}_{1}}$ captures the portion of $\mathrm{E}_{\mathrm{I} 1}$ that is correlated with $\mathrm{I}_{1}$, and $\mathrm{V}_{1}$ represents an exogenous error term. Finally, inserting Equation (6) into Equation (4), we obtain:

$$
\mathrm{Y}=\mathrm{B}_{\mathrm{X}} \mathrm{X}+\theta_{\mathrm{A}} \mathrm{I}_{1}-\theta_{\mathrm{A}} \hat{\alpha}_{1}-\theta_{\mathrm{A}} \gamma_{\delta} \hat{\delta}_{\mathrm{I}_{1}}-\theta_{\mathrm{A}} \widehat{\mathrm{V}}_{1}+\mathrm{E}
$$

In Equation (7) we have captured the respondent error of concern with regards to A, and through the use of a second indicator, as an instrument, resolved the problem of endogeneity. Thus, through Equation (7) consistent estimation becomes possible. The biggest challenge that remains is to find two additional indicators of a personal attribute, opinion, or attitude. One possible source for the first indicator is to ask the same question(s) of one's boss, roommate, or significant other. Given the task of serving as an instrument, finding the second valid indicator may be a challenging undertaking on behalf of the researcher. In the search for a valid second indicator, the second half of this paper will investigate a possible solution, the use of biomarkers in the human body, and of particular usefulness in marketing and behavioral research, the use of hormones and neurotransmitters in the human brain.

\section{Research Methods Borrowed From Neuroscience}

Before we discuss possible research methods borrowed from neuroscience that have the possibility to be used as a valid indicator in order to address respondent error, it is useful to put the relationship between neuroscience and survey research into perspective (Figure 1).

\begin{tabular}{|l|l|l|l|l|}
\hline The human brain & $\rightarrow$ & The human mind & $\rightarrow$ & Behavior \\
\hline Description: & & $\begin{array}{l}\text { Human consciousness (thoughts, } \\
\text { emotions, and attitudes) }\end{array}$ & Observable actions \\
\hline $\begin{array}{l}\text { Physical structures made of bundles of } \\
\text { neurons }\end{array}$ & & Survey research questionnaire & & $\begin{array}{l}\text { Physical } \\
\text { observation \& measurement }\end{array}$ \\
\hline Measurement: & $\begin{array}{l}\text { Neuroscience techniques: fMRI, qEEG, } \\
\text { and Neurotransmitter levels }\end{array}$ &
\end{tabular}

Figure 1. The brain-mind-behavior flow chart.

Figure 1 lays out the relationship among the human brain, mind, and behavior. It suggests that the structures and biochemistry of the human brain create the parameters in which the human mind exist, and the conscious decisions made in the human mind dictates one's behavior. Therefore, neuroscience research methods are used to determine the connections within the human brain that establish the strictures in which the human mind resides. Estimating the activity in the human brain provides a complimentary approach to better understand the responses formed in the human mind.

Currently there are many possible cognitive neuroscience methods to study the central nervous system, but they are beyond the scope of this paper. At present, researchers of human behavior are primarily utilizing three 
methods borrowed from neuroscience: the quantitative electroencephalogram (qEEG), the functional magnetic resonance imaging (fMRI), and measurement of biomarkers, including neurotransmitter and hormone levels in the central nervous system.

The electroencephalogram (EEG) has been used for years by psychologists to study the human brain. Neurons in the brain communicate with each other by sending electrically charged ions from the cell body along the axon in order to trigger the release of neurotransmitters into the synaptic gap. The amount of electrically charged ions activated in each region of the brain is measurable. Quantitative electroencephalogram (qEEG) measures electrical voltage fluctuations across different regions of the brain; and also measures the quantity of electrical current within each region of the brain, as well as the connectivity between brain regions (Hannah, Balthazard, Waldman, Jennings, \& Thatcher, 2013). qEEG has been used in organizational behavior studies to better understand the brains of leaders. For example, Hannah et al. (2013), studied electrical patterns in the brains of military leaders to better understand their ability to adapt their decision making in complex environmental conditions. The study was useful for better comprehending decision making on the field of battle. Waldman, Balthazard, and Peterson (2011) used qEEG testing to study the brains of inspirational leaders. Finally, Balthazard, Waldman, Thatcher, and Hannah (2012) investigated the electrical current patterns gathered from qEEG to detect differences in the brains of transformational vs. non-transformational leaders.

The fMRI takes images of regions of the brain based on blood flows. As an area of the brain becomes active, oxygen-rich blood flows to that region of the brain to fuel the neurons, and the fMRI maps changes in oxygen-rich blood flows in each area of the brain. As examples of recent organizational behavior research, Boyatzis, Passarelli, Koenig, Lowe, Mathew, Stoller, and Phillips (2012) examined employee memories of previous resonant and dissonant leaders by means of the fMRI. Also, Bagozzi, Verbeke, Dietvorst, Belschak, van den Berg, and Rietdijk (2013) used fMRI to study the roles of perspective taking and emotional sharing in order to better understanding Machiavellian behavior.

Moving from the analysis of brain regions down to the cellular level, the third research method measures the human brain based on biochemical activity. Individual neurons in the brain send a wide variety of chemicals called neurotransmitters across the synaptic gap to receptors on neighboring cells in order to develop complex thoughts, feelings, and also to send behavioral commands to the rest of the body (Kolb \& Whishaw, 2009). Measurement of biomarkers, including neurotransmitters provide a third important approach to measure activity in the central nervous system.

\section{Selection of a Neuroscience Method to Augment Current Survey Research}

If a researcher's goal is to build the most complete picture of the activity in the central nervous system with regards to a particular issue, ideally, one would utilize all three methods, qEEG, fMRI, and measurement of neurotransmitter levels, to measure (1) electrical activity; (2) blood flows; and (3) biochemical activity in each participant's brain. Unfortunately, in terms of feasibility, this may not be possible, if the research is using a survey that requires a large sample size. For example, once a sample size rises above 20 observations, it may not be feasible to attach electrodes to each participant's scalp while s/he answers questions. Likewise, it may not be realistic to request each person spend an hour or more in a fMRI neuroimaging procedure, especially if the sample is composed of administrators with full schedules.

By contrast, it may be feasible and not over burdensome, to request a swabbing of one's cheek with a cotton swab, a saliva sample (or a finger nail clipping or a few hairs), or that a finger-stick blood sample be 
submitted along with the completed questionnaire. Therefore based on the pragmatic issue of feasibility, both the qEEG and fMRI have important roles to play in clarifying and providing additional indicators in small samples or focus groups. For studies that utilize questionnaires and require a large sample size, the measurement of biomarker levels is the best suited research method from neuroscience for providing a vital second indicator. Therefore the following sections of this paper will present an overview of the estimation of neurotransmitters for behavioral research. After providing a general synopsis of the role neurotransmitters play in the function of the human brain, we will then provide more detailed information regarding the measurement procedures for estimating biomarker levels.

\section{Overview of Role of Neurotransmitters in Human Brain}

At the cellular level in the human brain, the brain is composed of approximately 170 billion cells, with roughly equal number of neuron and non-neuron cells, and communication between brain cells is required (Azevedo, Carvalho, Grinberg, Farfel, Ferretti, Leite, Filho, Lent, \& Herculano-Houzel, 2009). Neurons are the nerve cells residing in the brain, and Glia cells are the formal name for non-neuron brain cells. Using our computer analogy, if the human brain is a computer, the neurons are the microchips doing the data processing, and the glia cells form the motherboard on which the microchips reside, and also the frame to which the motherboard is attached. Glia cells also play the important role of the environmental regulation of the brain, including controlling levels of oxygen and electrically charged ions (sodium $\left(\mathrm{Na}^{+}\right)$, potassium $\left(\mathrm{K}^{+}\right)$, Chloride $\left(\mathrm{Ca}^{-}\right)$, and calcium $\left(\mathrm{Ca}^{2+}\right)$ ) available to neuron cells (Koob, 2009). Too many or too few available electrical ions will impair neuron function; but the brain is well protected by regulatory glia cells.

Human brain cells communicate with each other by sending a variety of chemicals across the synaptic cleft or gap between the two neurons. The transfer of information between neurons is known as synaptic transmission. The chemical messengers are called neurotransmitters. Individual synapses or gaps between neuron cells have two sides, the neuron sending the neurotransmitter at the axon terminal which is presynaptic, and the receptors on the receiving neuron form the postsynaptic density. As a rule, each neurotransmitter binds to a specific receptor within the postsynaptic density. However, for every receptor, there may be several subtypes to which a neurotransmitter can bind. Also, for every receptor subtype, there exist chemical agonists, which activate the receptor, and chemical antagonists, which inhibit neurotransmitter function (Bear et al., 2006).

\section{An Overview of Neurotransmitters}

Although communication between neurons in the brain via synapses may appear to be straight forward, the physiology of chemical transmission is intricate. Because of its complexity, heurobiologist separate transmission into four steps: (1) neurotransmitter synthesis and storage, (2) neurotransmitter release into the synaptic gap, (3) neurotransmitter reception and biological reactions, and (4) neurotransmitter recovery and degradation (See Figure 2).

On the presynaptic side, inside the axon terminal are mitochondria, which provide energy, ATP (adenosine triphosphate), for synaptic transmission; synaptic vesicles, which store and release small-molecule neurotransmitters; and secretory granules which store and release large-molecule peptide neurotransmitters. On the postsynaptic side, the postsynaptic density has three different possible locations: on a dendrite (an antenna for receiving information), on the axon of the receiving neuron (the neuron's antenna for sending information), 
or even on the soma (cell body), depending on neurotransmitter function (Kandel, Schwartz, Jessell, Siegelbaum, \& Hudspeth, 2012).

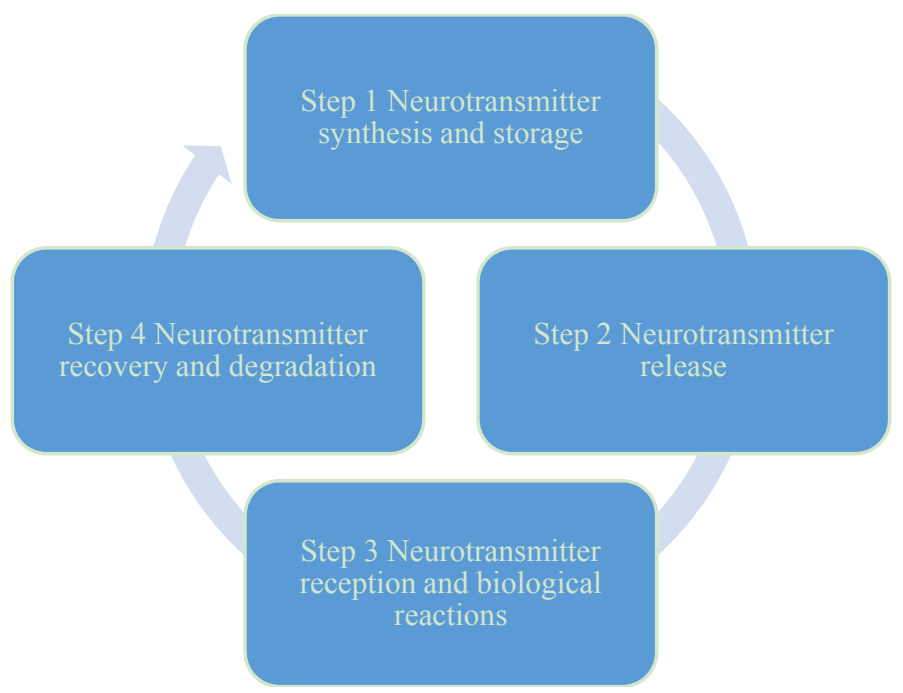

Figure 2. Steps in neurotransmitter transmission.

Once any neurotransmitter is released into the synaptic cleft and binds to a specific receptor protein in the postsynaptic density, the synaptic cleft must then be cleared of any residual neurotransmitter. The process of cleaning or resetting the synaptic gap is required before the next round of neurotransmission can occur. This clearing of the synaptic gap is part ofthe process of neurotransmitter recovery and degradation (Bear et al., 2006).

The cleaning of residual neurotransmitter from the synaptic gap is made possible by a class of membrane-transport proteins known as neurotransmitter transporters (Iversen et al., 2009). The role of these specialized proteins is transport neurotransmitters across the cellular membranes of each neuron. Their functions along the synaptic membrane include: transporting the neurotransmitter into the synaptic gap (neurotransmitter release); transporting any residual neurotransmitter from the synaptic gap back into the presynaptic axiom terminal (clearing the synaptic gap); and reloading neurotransmitters back into their synaptic vesicles (neurotransmitter recovery) (Kandel et al., 2012).

\section{Neurotransmitter Categories}

To date scientists have discovered three broad categories of neurotransmitters: (1) small molecule neurotransmitters, including: amino acids, monoamines, and acetylcholine; (2) large molecule neuro-peptides; and (3) gasotransmitters (Freberg, 2009) (See Table 2).

Table 2

Important Neurotransmitters

Amino Acids

Glutamate (Glu) — the most abundant excitatory neurotransmitter in the brain

Gamma-aminobutyric acid (GABA) and Glycine (GLY) - two major inhibitory neurotransmitters in the brain

Acetylcholine (Ach) — causes the contraction of skeletal muscles

Monoamines

Catecholamine family - each molecule is synthesized into a new molecule 
Table 2 to be continued

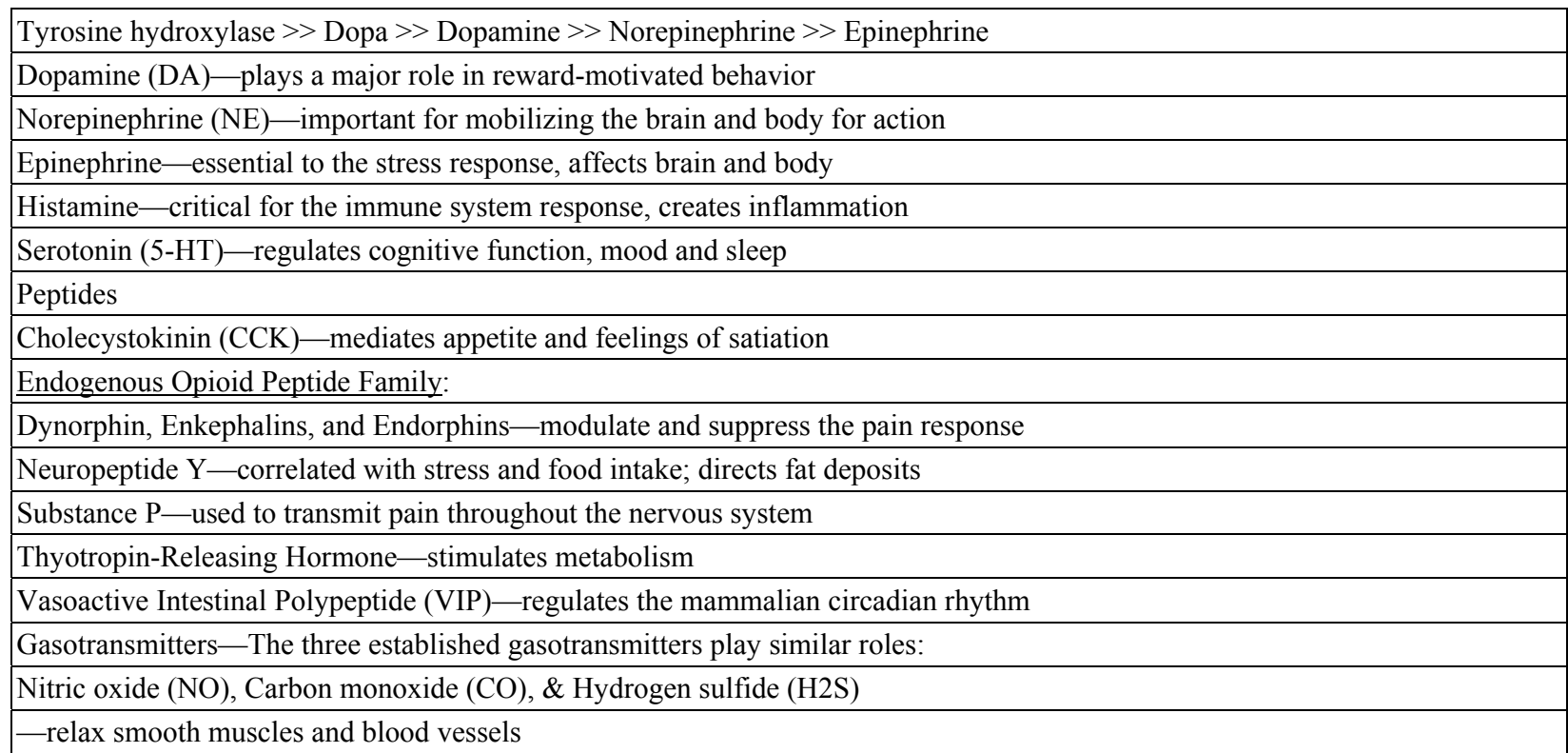

Source: All information taken from Bear et al., 2006.

At this point, we will introduce other important biomarkers in Table 3:

Table 3

Important Biomarkers for Use as Indicators

Alpha Amylase - protein enzyme that converts starch and Glycogen into glucose (sugar)

Cortisol-steroid hormone - stress hormone that increase blood sugar and suppresses immune system

Estrogen-female sex hormone and regulates female reproductive system

Ghrelin-gastric peptide, hormone that stimulates appetite

Oxytocin - peptide hormone - bonding hormone that reduces fear and anxiety

Peptide YY - peptide hormone - creates a sensation of feeling full after eating

Testosterone-anabolic steroid and male sex hormone

Source: All information taken from Freeberg, 2009.

\section{Measurement of Biomarkers Used in Behavioral Research}

All of the biomarkers listed in Tables 2 and 3 affect human behavior and therefore potentially could be used in organizational research. While biologists have the option to euthanize an animal and take brain tissue, the collecting of biomarkers in humans is more prohibitive. Ideally, measurement of neurotransmitter levels within the central nervous system should be taken from cerebral spinal fluid. But at present, it is not an acceptable practice to draw cerebral spinal fluid from human subjects for social science research. Therefore, it is the current protocol of research in the behavioral research, as well as the field of medicine, to use measurements of neurotransmitters drawn from plasma (blood), urine, or saliva as a proxy for biomarker levels in the central nervous system. The validity of this proxy has been accepted by practice, rather than by verified measurement.

In rats, the correlation between serotonin levels in urine and levels in brain slices is statistically significant (Lynn-Bullock, Welshhans, Pallas, \& Katz, 2004). In humans Marc, Ailts, Campeau, Bull, and Olson (2011) 
did a review of the medical literature and found evidence to support the use of neurotransmitter measurement from urine samples as a biomarker of neurotransmitter activity in the central nervous system. "The current body of literature provides evidence that neurotransmitters excreted in the urine may have a place in clinical practice as biomarkers of nervous system function" (Marc et al., 2011, p. 642 ). Given the established acceptance of biomarkers, Table 4 presents commonly used biomarkers:

Table 4

Measurements of Biomarker Currently Used in Behavioral Research

Alpha Amylase:

Alpha Amylase (sAA) - protein enzyme that converts starchinto glucose and maltose; biomarker for physical and psychological stress (Vineetha, Pai, Vengal, Gopalakrishna, \& Narayanakurup, 2014); also serves as a useful biomarker for anxiety (Rashkova, Ribagin, \& Toneva, 2012)

Test types: Saliva, blood, urine

Normal range: Urine - 6.5 to 48 SI units/hour blood-30-220 SI units/liter

Dopamine:

Dopamine-Used to focus the brain's attention (Treadway et al., 2012; Koepp et al., 1998); and creates a pleasurable sensation or a sense of reward (Burns, 2012); plays a role in learning from rewards (den Ouden et al., 2013)

Test type: urine, blood

Normal range (adults/elderly): $65-400 \mathrm{mcg} / 24$ hours

Serotonin:

Serotonin-Associated with a healthy immune system and cognitive performance (Zald \& Depue, 2001); low levels are associated with depression (Kendler et al., 2005; Lucki, 1998) and poor cognitive performance (Schmitt, Wingen, Ramaekers,

Evers, \& Riedel, 2006); plays a role in learning from negative events (den Ouden et al., 2013)

Test types: blood

Blood-normal range (adults): $\leq 230 \mathrm{ng} / \mathrm{mL}$

Testosterone:

Testosterone-Used as a proxy for: social aggression and also risk propensity/risk tolerance (Mesley, 2015)

Test type: saliva, blood

Blood-normal range: (adults age 20+)

\begin{tabular}{lll} 
& Males & Females \\
Free testosterone: & $41-239 \mathrm{pg} / \mathrm{mL}$ & $0.6-3.8 \mathrm{pg} / \mathrm{mL}$ \\
Total testosterone: & $280-1080 \mathrm{ng} / \mathrm{dL}$ & $<70 \mathrm{ng} / \mathrm{dL}$ \\
\hline
\end{tabular}

Cortisol:

Cortisol—Used as a proxy for: stress and fear in subjects (Rodriques et al., 2009)

Testosterone-to-Cortisol ratio is used as a proxy for proneness to social aggression (Terburg, Morgan, \& van Honk, 2009).

Testosterone and Cortisol are associated with "mistrust"; and Oxytocin and Serotonin are associated with "trust" and "approach behavior" (Riedl \& Javor, 2012).

Test types: blood, urine, and saliva Note: Cortisol levels rise during the night, and fall during the day

Normal range (adults):

Blood test: Urine test:

$8 \mathrm{am}: 5-23 \mathrm{mcg} / \mathrm{dL} \quad<100 \mathrm{mcg} / 24$ hours

$4 \mathrm{pm}: 3-13 \mathrm{mcg} / \mathrm{dL}$

Saliva:

7-9 am: 10-750 ng/dL

$3-5 \mathrm{pm}<401 \mathrm{ng} / \mathrm{dL}$

11 pm-midnight $<100 \mathrm{ng} / \mathrm{dL}$

Source: Measurement information taken from Pagana \& Pagana, 2014.

\section{Examples of Using Biomarker Measurement to Correct for Respondent Error}

The first example is a practice already in place to sample neurotransmitter levels in participants' urine of to correct for any respondent error on the questionnaire they are completing. For many jobs, one of the 
questions on the work application questionnaire is "Are you currently using illegal drugs?" In order to address response error (socially-desirably responding) of applicants who currently use illegal pharmaceuticals, but desire to get the job, many organizations also require applicants to submit a urine sample to test for exogenous opioids and cannabinoids.

A second example, in survey research, is for any self-reporting assessment given to managers/supervisors regarding their management style and effectiveness; a percentage of the sample will answer with some sort of socially-desirability responding or biased self-presentation strategy (Diebig, Bormann, \& Rowold, 2016). Most supervisors would not want to admit if one's management style is machiavellian or narcissistic. Thus, a useful secondindicator to augment the self-reporting questionnaire would be measurement of endogenous testosterone, as an indicator for social aggression (Mesley, 2015; Bos, Terburg, \& van Honk, 2010; Ronay \& Carney, 2013) and/or cortisol levels in their subordinates, as an indicator for work-place stress (Diebig et al., 2016).

In the final example, there is social stigma to being diagnosed and treated for depression (Givens, Katz, Bellamy, \& Holmes, 2007). Because of the social stigma, many people are reluctance to share their struggle with depression (Givens et al., 2007). As a result, Kolstad, Hansen, Kærgaard, Thomsen, Kaerlev, Mikkelsen, and Andersen (2011) found significant bias in incidents of depression when self-reporting.

Lack of independent measures of psychosocial exposures and the risk of reporting bias is probably the most important reason that causal relations between adverse psychosocial exposures and mental health outcomes remain a controversial issue in spite of several large prospective follow-up studies. (Kolstad et al., 2011, p. 94 )

To overcome this issue of underreporting of major depression in survey research, a critical measurement would be the one's level of serotonin in the central nervous system (Kendler, Kuhn, Vittum, Prescott, \& Riley, 2005; Lucki, 1998; Zald \& Depue, 2001).

\section{The Human Genome and the Use of Genotyping for Behavioral Research}

The mapping of the human genome has provided a new class of biomarkers with useful applications in behavioral research. Given the complexity of human physiology, and the possibility of numerous potential confounds when attempting to model behavior in biologically complex organisms, neuroscientists are now beginning to explore the human genome as a starting point for neurotransmitter research (den Ouden, Daw, Fernandez, Elshout, Rijpkema, Hoogman, Franke, \& Cools, 2013). The use of each participant's genotype as an indicator for use in behavioral research has an additional advantage. Because each person's DNA (deoxyribonucleic acid) never changes, the use of genotyping can be used as an exogenous variable when modeling human behavior.

The human genome refers to the entire DNA in the human body (both in the cell nucleus and mitochondria DNA). In April 2003, the Human Genome Project sequenced the entire DNA (i.e., inherited instructions) in the human body. Within the 23-paired chromosomes lies the human DNA. The human DNA is composed of approximately three billion nucleotides (Cavalli-Sforza, 1990). There are only four types of nucleotide: adenine (A), guanine (G), cytosine (C), and thymine (T). Two different types of nucleotide connect together to form the center "spokes" of our DNA, in between two sugar-phosphate backbone that create the double helix DNA. Nucleotide type A pairs with T, and C goes with G, to form the base pair spokes of the double helix.

Specific sections of our DNA are called genes. Each gene is a recipe to direct the manufacturing of either a specific protein or polypeptide RNA molecule. Each gene has a specific starting and ending point along our 
string of DNA. The rest (majority) of our DNA is called noncoding DNA. The purpose of noncoding DNA is to regulate the activation of our genes (Encode Consortium, 2012). Although our understanding of the exact processes by which noncoding DNA operate is still limited, noncoding DNA activates each gene to make a specific protein.

Our DNA, is a string of three billion nucleotides, and with each paired spoke being either A-T, or C-G. Reading our DNA is similar a computer reading a digital message, or a long string of 0's and 1's. In humans, the shortest gene, histone H1a, is 781 paired nucleotides long, and the longest, dystrophin, is 2.2 million base pairs long (Source: Ensembl genome browser release 68, July 2012). Therefore, each human gene contains a finite amount of information as a recipe for synthesizing either a specific protein or polypeptide RNA molecule.

In order to use the sequencing of nucleotides within a gene to predict neurotransmitter behavior in the central nervous system, three steps are required. The first step is the mapping of the human genes. Each gene is responsible for synthesizing a specific protein or polypeptide RNA molecule. For example the genes that encode both the serotonin transporter and dopamine transporter proteins have been identified (den Ouden et al., 2013).

The second step is to identify a single nucleotide polymorphism (SNP) within the gene. In each gene the nucleotides are arranged in a specific sequence. For identification purposes, only one paired nucleotide can be changed within the sequence (see Figure 3).

\begin{tabular}{|l|l|l|l|l|}
\hline \multirow{2}{*}{ Genotype I } & A & C & A & A \\
\cline { 2 - 5 } & T & G & T & T \\
\hline \multirow{2}{*}{ Genotype II } & A & C & T & A \\
\cline { 2 - 5 } & T & G & A & T \\
\hline \multirow{2}{*}{ Genotype III } & C & C & A & A \\
\cline { 2 - 5 } & G & G & T & T \\
\hline
\end{tabular}

Figure 3. Polymorphs of a fictitious 4-paired-nucleotide gene.

If two or more polymorphisms have occurred within the sequence of nucleotides, then it may be impossible to tell which polymorphism is responsible for the specific effect being investigated. Also, the single nucleotide polymorphism must be widespread within the human population. For research purposes, a sample of the population must contain enough observations of the different variations of the polymorphism that a significant percentage of each variety of the SNP (or each genotype) is present in the sample.

The third step is to genotype a sample for each single nucleotide polymorph and test the effect of the genotype variations on either human behavior or physiological function, including neurotransmitter levels. Therefore, the genotyping of single nucleotide polymorphism (SNP) creates a new approach to studying neurotransmitters based on genetic differences. The advantage of this new approach based on genotyping, is it utilizes a true exogenous variable as a starting point for studying human behavior. Also, as the cost of genotyping SNP's continually decreases, testing for single nucleotides polymorphs may be a potential method to obtain a third indicator to be used as an instrument to correct for the endogeneity caused by response errors. Finally, as certain polymorphs of specific genes are found to impede proper levels or function of a biomarker in the central nervous system, genotyping can produce useful indicators for a variety of topics in organizational and psychological research. 


\section{Correlations Between Human Genotypes and Behavior}

In the field of medicine researchers have found a number of diseases are directly caused by single nucleotide polymorphs of specific genes. For example sickle cell anemia is caused by a specific SNP of the $\beta$-globin gene, which results in malformed hemoglobin within red blood cells (Pawliuk, Westerman, Fabry, Payen, Tighe, Bouhassira, Acharya, Ellis, London, Eaves, Humphries, Beuzard, Nagel, \& Leboulch, 2001).

But the relationship between human genotypes and human behavior is less clear. Human genes create proteins that are useful to perform a certain function or aid in a specific behavior. These proteins are purposeful in function. By contrast, human behavior results from the intersection of three different sources, namely, one's external environment, one's DNA, and a person's history (established patterns) of desires, preferences, and behavior. Therefore neuroscientists do not refer to SNP's as driving behavior. Rather, scientists use the nomenclature of providing evidence for a correlation between a particular SNP and a measurable behavior or outcome.

For example, participants with the seven-repeat (7R) SNP of the dopamine-4 receptor gene (DRD4) were found to have a greater release of dopamine from consumption of sugar than non-carriers (Silveira et al., 2014). Under stressful conditions, carriers of the 7R SNP of DRD4 preferred a diet with a higher sugar content than non-carrier participants, and also a tendency towards obesity, depending on the external environment (Silveira et al., 2014).

Likewise, in the human body, the two main enzymes that are responsible for the metabolism of alcohol (ethanol) are: alcohol dehydrogenase (ADH) and aldehyde dehydrogenase (ALDH). Polymorphisms (SNP's) of both ADH and ALDH alter each enzyme's ability to metabolize alcohol (Edenberg, 2007). SNP's of both ADH and ALDH among a number of ethnic groups including certain tribes of Native Americans have been found to reduce the speed of metabolism of alcohol (Edenberg, 2007).

The ratio of the reduction in speed of metabolism between ADH and ALDH has been found to make certain ethnic groups more prone to alcoholism than other groups carrying slightly different ratios based on underlying genotypes of the two enzymes (Edenberg, 2007).

\section{Conclusions}

Respondent error has been a problem since the beginning of survey research that uses the questionnaire. Because respondent error lies beyond the control of the researcher, until present there have been no suitable research methods to correct for this problem. To address the issue of respondent error we require the use of two additional indicators beyond the questionnaire. In order to measure the magnitude of the error, the first indicator should come from an outside person who knows the tendencies of the participant. Measurement of biomarkers, including neurotransmitter and hormone levels may be useful in providing the second additional required indicator that also must serve as an instrument. This multiple indicators approach among the human mind, the human brain, and an outside observer, makes possible to overcome otherwise unmeasurable response errors from participants that calls into question the capacity of using self-reporting questionnaires to produce consistent results.

The mapping of the human genome has created critically important exogenous variables for neuroscience research. The genotyping of single nucleotide polymorphism (SNP) within specific genescreates a new approach to studying neurotransmission in the central and peripheral nervous systems. Because human genetics is inherited and fixed, the genotype variations of a single nucleotide polymorphism are a true exogenous 
variable for studying environmental influences on human behavior. Finally, the verification of the DNA genotype for each participant may be an additional indicator for the purpose of correcting for respondent errors. So, in conclusion, through the use of three independent measurements, researchers are able to address the critical confound of respondent error and achieve consistent estimation in traditional survey research. The challenge of this approach will be to find two additional valid indicators of each response in question.

\section{References}

Antonakis, J., Bendahan, S., Jacquart, P., \& Lalive, R. (2010). On making causal claims: A review and recommendations. The Leadership Quarterly, 21, 1086-1120.

Azevedo, F. A. C., Carvalho, L. R. B., Grinberg, L. T., Farfel, J. M., Ferretti, R. E. L., Leite, R. E. P., Filho, W. J., Lent, R., \& Herculano-Houzel, S. (2009). Equal numbers of neuronal and nonneuronal cells make the human brain an isometrically scaled-up primate brain. Journal of Comparative Neurology, 513(5), 532-541.

Bagozzi, R. P., Verbeke, W. J., Dietvorst, R. C., Belschak, F. D., van den Berg, W. E., \& Rietdijk, W. J. (2013). Theory of mind and empathic explanations of Machiavellianism a neuroscience perspective. Journal of Management, 39(7), 1760-1798.

Balthazard, P., Waldman, D. A., Thatcher, R. W., \& Hannah, S. T. (2012). Differentiating transformational and non-transformational leaders on the basis of neurological imaging. The Leadership Quarterly, 23, 244-258.

Barsade, S. G., Ramarajan, L., \& Westen, D. (2009). Implicit affect in organizations. Research in Organizational Behavior, 29, 135-162.

Baruch, Y., \& Holtom, B. C. (2008). Survey response rate levels and trends in organizational research. Human Relations, 61(8), $1139-1160$.

Bear, M. F., Connors, B. W., \& Paradiso, M. A. (2006). Neuroscience: Exploringthe brain (3rd ed.). Baltimore: Lippincott Williams and Wilkins.

Becker, W. J., Cropanzano, R., \& Sanfey, A. G. (2011). Organizational neuroscience: Taking organizational theory inside the neural black box. Journal of Management, 37, 933-961.

Bickle, J. (2006). Reducing mind to molecular pathways: Explicating the reductionism implicit in current cellular and molecular neuroscience. Synthesis, 151, 411-434.

Borkenau, P., \& Zaltauskas, K. (2009). Effects of self-enhancement on agreement on personality profiles. European Journal of Personality, 23(2), 107-123.

Bos, P. A., Terburg, D., \& van Honk, J. (2010). Testosterone decreases trust in socially naïve humans. Proceedings of the National Academy of Sciences, 107(22), 9991-9995.

Boyatzis, R. E., Passarelli, A. M., Koenig, K., Lowe, M., Mathew, B., Stoller, J. K., \& Phillips, M. (2012). Examination of the neural substrates activated in memories of experiences with resonant and dissonant leaders. The Leadership Quarterly, 23(2), 259-272.

Burns, M. (September 18, 2012). Dopamine and learning: What the brain's reward center can teach educators. Scientific Learning Blog. Retrieved from Dec. 15, 2014, http://www.scilearn.com/blog/dopamine-learning-brains-reward-center-teach-educators

Cavalli-Sforza, L. (1990). Opinion: How can one study individual variation for 3 billion nucleotides of the human genome? Am J. Hum Genet, 46(4), 649-651.

Cialdini, R. B., \& Goldstein, N. J. (2004). Social influence: Compliance and conformity. Annu. Rev. Psychol., 55, 591-621.

Cunningham, W. A., Zelazo, P. D., Packer, D. J., \& Van Bavel, J. J. (2007). The iterative reprocessing model: A multilevel framework for attitudes and evaluation. Social Cognition, 25(5), 736-760.

Den Ouden, H., Daw, N. D., Fernandez, G., Elshout, J. A., Rijpkema, M., Hoogman, M., Franke, B., \& Cools, R. (2013). Dissociable effects of dopamine and serotonin on reversal learning. Neuron, 80(4), 1090-1100.

Diebig, M., Bormann, K. C., \& Rowold, J. (2016). A double-edged sword: Relationship between full-range leadership behaviors and followers' hair cortisol level. The Leadership Quarterly, 27(4), 684-696.

Edenberg, H. J. (2007). The genetics of alcohol metabolism: Role of alcohol dehydrogenase and aldehyde dehydrogenase variants. Alcohol Research \& Health, 30(1), 5-13.

Epley, N., \& Dunning, D. (2000). Feeling "holier than thou": Are self-serving assessments produced by errors in self-or social prediction? Journal of Personality and Social Psychology, 79(6), 861.

Freberg, L. (2009). Discovering biological psychology (2nd ed.). Independence: Wadsworth Publishing. 
Ganster, D. C., Hennessey, H. W., \& Luthans, F. (1983). Social desirability response effects: Three alternative models. Academy of Management Journal, 26(2), 321-331.

Givens, J. L., Katz, I. R., Bellamy, S., \& Holmes, W. C. (2007). Stigma and the acceptability of depression treatments among African Americans and whites. Journal of General Internal Medicine, 22(9), 1292-1297.

Hannah, S. T., Balthazard, P. A., Waldman, D. A., Jennings, P., \& Thatcher, R. (2013). The psychological and neurological bases of leader self-complexity and effects on adaptive decision-making. Journal of Applied Psychology, 98, 393-411.

Hausman, J. (1978). Specification tests in econometrics. Econometrica, 46(6), 1251-1271. doi:10.2307/1913827

Iversen, L., Iversen., S., Bloom, F., \& Roth, R. (2009). Introduction to neuropsychopharmacology. Oxford: Oxford University Press.

Kandel, R., Schwartz, J., Jessell, T., Siegelbaum, S., \& Hudspeth, A. (2012). Principles of neural science (5th ed.). New York: McGraw Hill.

Kendler, K. S., Kuhn, J. W., Vittum, J., Prescott, C. A., \& Riley, B. (2005). The interaction of stressful life events and a serotonin transporter polymorphismin the prediction of episodes of major depression: A replication. Archives of General Psychiatry, 62, 529-535.

Koepp, M. J., Gunn, R. N., Lawrence, A. D., Cunningham, V. J., Dagher, A., Jones, T., Brooks, D. J., Bench C. J., \& Grasby, P. M. (1998). Evidence for striatal dopamine release during a video game. Nature, 393, 266-268.

Kolb, B., \& Whishaw, I. Q. (2009). An introduction to brain and behavior (3rd ed.). New York: Worth Publishers.

Kolstad, H. A., Hansen, Å. M., Kærgaard, A., Thomsen, J. F., Kaerlev, L., Mikkelsen, S., \& Andersen, J. H. (2011). Job strain and the risk of depression: is reporting biased? American Journal of Epidemiology, 173(1), 94-102.

Koob, A. (2009). The root of thought: Unlocking glia. Upper Saddle River: FT Science Press.

Leary, M. R., \& Kowalski, R. M. (1990). Impression management: A literature review and two-component model. Psychological Bulletin, 107(1), 34 .

Lieberman, M. D. (2007). Social cognitive neuroscience: A review of core processes. Annual Review of Psychology, 58, $259-289$.

Lucki, I. (1998). Biological Psychiatry, 44(3), 151-162.

Lynn-Bullock, C. P., Welshhans, K., Pallas, S. L., \& Katz, P. S. (2004). The effect of oral 5-HTP administration on 5-HTP and 5-HT immunoreactivity in monoaminergic brain regions of rats. J. Chem Neuroanat, 27(2), 129-138.

Marc, D. T., Ailts, J. W., Campeau, D. C. A., Bull, M. J., \& Olson, K. L. (2011). Neurotransmitters excreted in the urine as biomarkers of nervous system activity: Validity and clinical applicability. Neuroscience \& Biobehavioral Reviews, 35(3), 635-644.

Mesly, O. (2015). Creating models in psychological research. New York: Springer.

Pagana, K., \& Pagana, T. (2014). Moby's manual of diagnostic and laboratory tests (5th ed.). St. Louis: Elsevier.

Paulhus, D. L. (1984). Two-component models of socially desirable responding. Journal of Personality and Social Psychology, 46(3), 598.

Pawliuk, R., Westerman, K. A., Fabry, M. E., Payen, E., Tighe, R., Bouhassira, E. E., Acharya, S. A., Ellis, J., London, I. M., Eaves, C. J., Humphries, R. K., Beuzard, Y., Nagel, R. L., \& Leboulch, P. (2001). Correction of sickle cell disease in transgenic mouse models by gene therapy. Science, 294(5550), 2368-2371.

Purves, D., Augustine, J. G., Fitzpatrick, D., Hall, W. C., LaMantia, A.-S., McNamara, J. O., \& White, L. E. (2008). Neuroscience (4th ed.). Sunderland: Sinauer Associates.

Rashkova, M. R., Ribagin, L. S., \& Toneva, N. G. (2012). Correlation between salivary $\alpha$-amylase and stress-related anxiety. Folia Medica, 54(2), 46-51.

Riedl, R., \& Javor, A. (2012). The biology of trust: Integrating evidence from genetics, endocrinology, and functional brain imaging. The Journal of Neuroscience, Psychology, and Economics, 5(2), 63-91.

Rodrigues, S. M., LeDoux, J. E., \& Sapolsky, R. M. (2009). The influence of stress hormones on fear circuitry. Annual Review of Neuroscience, 32, 289-313.

Ronay, R., \& Carney, D. R. (2013). Testosterone's negative relationship with empathic accuracy and perceived leadership ability. Social Psychological and Personality Science, 4(1), 92-99.

Schmitt, J. A., Wingen, M., Ramaekers, J. G., Evers, E. A., \& Riedel, W. J. (2006). Serotonin and human cognitive performance. Curr Pharm Des, 12(20), 2473-2486.

Silveira, P. P., Portella, A. K., Kennedy, J. L., Gaudreau, H., Davis, C., Steiner, M., ... Levitan, R. D. (2014). Association between the seven-repeat allele of the dopamine-4 receptor gene (DRD4) and spontaneous food intake in pre-school children. Appetite, 73, 15-22. 
Terburg, D., Morgan, B., \& van Honk, J. (2009). The testosterone-cortisol ratio: A hormonal marker for proness to aggression. International Journal of Law and Psychiatry, 32, 216-223.

The ENCODE Project Consortium. (2012). An integrated encyclopedia of DNA elements in the human genome. Nature, 489(7414), 57-74.

Treadway, M. T., Buckholtz, J. W., Cowan, R. L., Woodward, N. D., Li, R., Ansari, M. S., Baldwin, R. M., Schwartzman, A. N., Kessler, R. M., \& Zald, D. H. (2012). Dopaminergic mechanisms of individual differences in human effort-based decision-making. Journal of Neuroscience, 32(18), 6170-6176.

Vazire, S. (2010). Who knows what about a person? The self-other knowledge symmetry (SOKA) model. Journal of Personality and Social Psychology, 98(2), 281.

Vineetha, R., Pai, K. M., Vengal, M., Gopalakrishna, K., \& Narayanakurup, D. (2014). Usefulness of salivary alpha amylase as a biomarker of chronic stress and stress related oral mucosal changes-a pilot study. Journal of Clinical and Experimental Dentistry, 6(2), e132-e137. PMC. Accessed Web. 6 Sept. 2017.

Waddell, S. (2013). Reinforcement signaling in drosophila; dopamine does it all after all. Current Opinion in Neurobiology, 23(3), 324-329.

Waldman, D. A., Balthazard, P. A., \& Peterson, S. (2011). The neuroscience of leadership: Can we revolutionize the way that leaders are identified and developed? Academy of Management Perspectives, 25(1), 60-74.

Westen, D. (2007). The political brain: The role of emotion in deciding the fate of the nation. New York: Public Affairs.

Wooldridge, J. (2010). Econometric analysis of cross section and panel data. Cambridge, Massachusetts: MIT Press.

Zald, D. H., \& Depue, R. A. (2001). Serotonergic functioning correlates with positive and negative affect in healthy males. Personality and Individual Differences, 30, 71-86. 